\title{
The Use of a Simplex Method with an Artificial basis in Modeling of Flour Mixtures for Bakery Products
}

\author{
Natalia A. Berezina \\ Food Technology and Organization of Restaurant Business \\ Orel State University \\ Orel, \\ Russian Federation
}

\author{
Andrey V. Artemov \\ Information System \\ Orel State University \\ Orel, \\ Russian Federation
}

\author{
Igor A. Nikitin \\ Technology of Grain Processing, Bakery, Pasta and \\ Confectionery Industries \\ K.G. Razumovsky Moscow State University of \\ Technologies and Management (The First Cossack \\ University) Moscow, Russian Federation
}

Igor V. Zavalishin

K.G. Razumovsky Moscow State University of Technologies and Management

(The First Cossack University)

Moscow, Russian Federation

\author{
Andrey N. Ryazanov \\ Machines and Equipment for Food Production \\ Voronezh State University of Engineering Technologies \\ Orel, Russian Federation
}

\begin{abstract}
Modeling of flour mixtures for bakery products of increased biological value is done. The problem is solved by a simplex method with an artificial basis related to numerical optimization methods for solving linear programming problems. A mathematical model of the composition of a polycomponent flour mixture has been constructed. The model is taking into account the minimal amount of essential amino acids. An automated scientific research system for modeling the composition of flour mixtures with specified functional characteristics was developed and implemented. The composition of flour mixes for bakery products has been optimized according to the target values of the amino acid score and biological value. Application of the developed software package allows creating prescription compounds for rye-wheat bread with a 6.12-17.66\% higher biological value than traditional bakery products.
\end{abstract}

Keywords-Modeling; simplex method; polycomponent flour mixture; bakery products; biological value; quality

\section{INTRODUCTION}

The most important branch of the economy of any country is the food industry, which occupies a central position in the processing of agricultural raw materials and food supply. The fact determines its social significance for the population. However, scientific research in this industry is characterized by low intensity, associated with some inertia in the introduction of industrial production. Nevertheless, knowledge-based approaches and innovative solutions are an important tool for the food industry, since they make it possible to increase the competitiveness of products by meeting the expectations of consumers. A promising direction in this area is the creation of food products with a purposefully changed chemical composition of functional purpose [2], [7]. Functional products are gaining popularity among consumers. This is largely due to the increase in the cost of health care and life expectancy, as well as the desire to improve its quality among older consumers [6].

The complexity of the task of calculating food formulas is compounded by a large number of used types of basic and auxiliary raw materials and other prescription ingredients. Therefore the calculation of formulations is associated with the implementation of a large volume of routine calculations. It requires considerable time and has a high probability of occurrence and accumulation of errors in calculations. The solution of such problems is impossible without the use of modern computer technologies [5].

The automated design of new materials [9], including food formulas, is becoming increasingly important in scientific research. It happens largely due to the increased capabilities of modern computing facilities [4].

Automated design of formulations makes it possible to create a food product with the required characteristics of food and biological value quickly and relatively cheaply. It is done on the basis of scientifically grounded approaches to the selection of food ingredients [10].

The purpose of this work is the development of a software package for the automated calculation of the composition of a flour mixture for bakery products with increased biological value by optimizing the protein composition. 


\section{StATEMENT AND ANALYSis OF THE PROBLEM OF DEVELOPMENT OF THE AUTOMATED SCIENTIFIC RESEARCH SYSTEM FOR MODELING THE OPTIMIZED BREAD FLOUR PROTEIN AMINO ACID COMPOSITION}

The absence of a product in nature, in which all the substances necessary for the body would be, can be filled with a combination of the ingredient composition of food recipes. In this regard, the creation of enriched multicomponent formula compositions of flour mixtures for bread, having a chemical composition corresponding to modern physiological norms of nutrition is an actual problem [1].

The protein component of food, being its key component, determines the nature of nutrition as a whole. The physiologically necessary level of the protein makes it possible to manifest in the body the functions of other food components. The products must contain a certain amino acid composition of the protein, which includes interchangeable and irreplaceable amino acids. In this case, the most important is the content of essential amino acids. The absence of at least one indispensable amino acid in a protein makes it possible to consider it biologically inferior. In a protein of food products, the amount of essential amino acids can be significantly greater or less than their number in the FAO / WHO standard [3]. That is why when setting the task of developing an automated research system for calculating the optimized protein composition; formalization takes into account the interbalance of essential amino acids. The closer this ratio to the ideal recommended by FAO / WHO is, the more useful and balanced is the composition of this product.

To justify the formulation of polycomponent mixtures for bakery production, methods of mathematical modeling of a composition can be used.

In this case the raw components of a mixture with high protein content and biological value are pre-selected.

Optimization of the composition of flour mixtures was carried out according to the indicator of biological value.

$$
\begin{aligned}
& B C=100-K R A S \\
& K R A S=\frac{\sum A K_{\text {score }}-A K_{\text {lim it }}}{8}
\end{aligned}
$$

Where, $B C$ - the biological value of the protein in the flour mixture formula:

$K R A S$ - the difference coefficient of the amino acid score;

$A K_{\text {score }}$ - the amino acid score of a certain essential amino acid, a fraction of units;

$A K_{\text {limit }}$ - the amino acid score of the limiting amino acid, a fraction of units.

Biological value is a complex characteristic showing the quality of the protein components in the mixture. The lower the KRAS, the higher is the biological value of the protein mixture.

To develop an effective algorithm for calculating the composition of a mixture that is effective in time and accuracy, it is necessary to analyze the given subject area and the problem posed. In general, the problem is formulated as follows: to simulate the component composition of a mixture for bakery products, providing the content of essential amino acids not lower than the set value; the component composition should contain maximum amount of protein, provide a given ratio of proteins to carbohydrates $(4: 1)$ and have the taste properties that satisfy the majority of consumers. Such a problem can be reduced to the problem of linear programming, where the rate of a biological value of protein in the resulting flour mixture is chosen as the objective function, and the restrictions will set the necessary minimum values for important amino acids and trace elements. Then the resulting problem will be solved by a simplex method with an artificial basis, which can cause difficulties inherent in the implementation of the artificial base method. However, the most important condition that does not allow the use of methods for solving linear programming problems will be that it is extremely difficult to formalize the determination of the organoleptic and taste properties of bread obtained from this mixture.

The task in question consists of two stages: setting the necessary initial data on the ingredients of the mixture and amino acids and actually carrying out the necessary calculations.

The selection of the components of the mixture was carried out on the basis of an analysis of the literature data [8]. The characteristics of raw ingredients for calculating the composition of a flour mixture for bakery products is presented in Table I.

As can be seen from the data presented in Table I, the selected raw materials contain 1.3-4.9 times more essential amino acids, 1.4-9.7 times more protein than rye and wheat flour. In this case, the greatest biological value has the milk powder, egg powder, soy flour and sesame.

TABLE I. CHARACTERISTIC OF RAW MATERIAL COMPONENTS FOR FLOUR MIXTURE

\begin{tabular}{|l|l|l|l|}
\hline \multirow{2}{*}{$\begin{array}{l}\text { Name of raw } \\
\text { materials }\end{array}$} & $\begin{array}{l}\text { Indicator values } \\
\text { Protein, mg per }\end{array}$ & $\begin{array}{l}\text { Essential amino } \\
\text { acids, mg per } \\
\mathbf{1 0 0} \text { g }\end{array}$ & $\begin{array}{l}\text { Biological value } \\
(\%)\end{array}$ \\
\hline Rye flour & 11.7 & 3419 & 55 \\
\hline Wheat flour & 8.9 & 4115 & 62 \\
\hline Buckwheat flour & 14.0 & 4577 & 66 \\
\hline Lentil & 24.8 & 9620 & 67 \\
\hline Soy flour & 48.9 & 14240 & 74 \\
\hline $\begin{array}{l}\text { Dry Skim Milk } \\
\text { (DSM) }\end{array}$ & 37.9 & 16628 & 85 \\
\hline Sesame seeds & 19.8 & 7101 & 73 \\
\hline Sunflower seeds & 20.7 & 7419 & 56 \\
\hline Egg powder & 46.0 & 20480 & 87 \\
\hline Gelatine & 87.2 & 13460 & 67 \\
\hline Mustard seeds & 37.1 & 9094 & 67 \\
\hline
\end{tabular}


The solution of the problem is possible by constructing a complex additive objective function with weight coefficients, the values of which must be determined by experts. This turns into a serious problem with a standard approach to solving the task.

It can be concluded that the process of obtaining the optimal composition of a bakery mixture is a complex scientific task for the solution of which it is necessary to develop and implement an automated system of scientific research.

\section{AlGORITHM OF WORK OF THE SYSTEM OF SCIENTIFIC RESEARCH: MATHEMATICAL FORMALIZATION}

The algorithm of operation of such a system consists in the implementation of two successive processes: "generate a solution - check the solution", i.e. in obtaining a certain mixture and checking it for compliance with the specified constraints. This will allow us to obtain a set of solutions close to optimal, taking into account the user's requirements by varying the parameters of the objective functions: deviation from the optimal values and the maximum deviation from the calculated parameters (for example, for carbohydrate to protein ratio). Such a method will make it possible to quickly and efficiently modify the model, if necessary, by adding or changing restrictions, or by introducing new private objective functions.

The proposed method is possible due to the increased capabilities of modern computing facilities, when even a complete search of all the options for the composition of a mixture of ten components, where each component can take 100 different values (for example, varies from 0 to $100 \%$ in one unit of mass of the mixture), takes only a few minutes . Such a time cost of calculating the model is acceptable and allows us to use the proposed principle in scientific research. Such a solution is actually a full-factorial computational experiment, where the mass fractions of components of the flour mixture act as factors. This will allow investigating all the options for obtaining a flour mix, and changing the parameters of the model will make it possible to obtain solutions with different degrees of accuracy necessary in various situations.

Thus, the algorithm for obtaining variants of the composition of a polycomponent flour mixture for a given set of constraints and objective functions is realized using the following steps:

1) Set the initial data for calculating the mixture parameters. At this step, the possible components of the mixture are set, as well as their quantitative characteristics.

2) Specify the intervals and steps for changing the components of the mixture. Setting of these parameters will allow to limit the mass fraction of each component of the mixture, depending on the needs and tasks of a researcher, and setting the step of changing the mass fraction of each component will provide the necessary accuracy for further calculation of the mixture and its physical production.
3) Selection of components used in the mixture. At this stage, it is possible to select only those products that should be used in the mixture.

4) Setting the minimum value of the biological value of the resulting mixture. The parameter allows us to limit the number of obtained optimal solutions, making it possible to generate mixtures with a very high biological value. Reduction of this parameter will allow increasing the number of mixture variants obtained to evaluate them by other parameters.

5) Setting the maximum deviation from the optimal ratio of carbohydrates to proteins in the mixture. Strict fulfillment of the optimal ratio of carbohydrates to proteins (4:1) is very difficult to attain when obtaining specific variants of the mixture, so setting this parameter will make it possible to obtain mixtures that are close to optimal with a given deviation value.

6) Carrying out calculations.

7) Analyze the results obtained, change the model parameters and run a new model if necessary.

8) Use of the obtained variants of the mixture for carrying out field experiments.

To date, this problem is solved by the following methods: the use of standard components of optimization in packages of office programs, application of the Monte Carlo method, the Newton method, the simplex method. Let's consider the existing methods and software implementations using various applications and environments.

The modeling of compositions of well-balanced mixtures is carried out using various approaches. One of them suggests the optimization of the composition of dishes based on the balance of needs in certain substances with specified restrictions [11]. The disadvantage of the proposed optimization method is the difficulty in providing the processability of optimized ingredient compositions and cumbersome calculations. An increase in the nutritional and biological value of bread was established with the introduction of protein concentrates by increasing digestibility and improving the qualitative and quantitative amino acid composition of products.

To date, tools have been developed in the form of methods for assessing the competitiveness of enterprises of the baking industry and the level of quality of bakery products, packages of applied programs [12]. The disadvantage of the proposed method is the use of such indexes as competitiveness and quality level as criteria for optimizing the composition of bakery products by introducing only protein concentrate without taking its balance with carbohydrates and changing the mineral composition of bakery products into account. Similar shortcomings are inherent in works aimed at improving the biological value of products due to the introduction of one or two ingredients without taking into account the important food components of the diet such as the content of minerals, their balance, as well as the balance of proteins and carbohydrates in the product [13]. 
The approach proposed by the authors to the design of composite mixtures for bakery products [14]-[16] suggests the use of applied computer programs for the formation of their composition. However, in this case, not all the composition of the flour mixture is formed, but only a certain component, i.e. protein supplement is recommended, the dosage of which must be determined additionally.

An approach is proposed for the design of mixtures in which the glycemic index is proposed as an optimization criterion [17]. However, the glycemic index characterizes only the carbohydrate component of the mixtures, which cannot serve as an unambiguous criterion for the formation of their composition.

There are various software products for calculating formulas. One of the most common is the use of an office application MS Excel [18]. The drawback of this method of calculation is the inconvenience of use due to the lack of automated data entry, obtaining a single result for the given parameters, the lack of flexibility in evaluating the optimality criteria.

Special software complex Elaton allows you to design multicomponent product recipes. A significant disadvantage is the lack of the possibility of multicriteria optimization. The program complex "Development of formulas of compositions from plant raw materials" is intended for calculation of food concentrates of high biological value. The disadvantage of this program is the lack of the possibility of optimizing prescriptions for amino acid composition.

The "Expert-Soft" company offers a software complex "Technologist-baker", "Technologist-confectioner", "Technologist-culinary" intended for food industry enterprises. These programs are designed to develop technological documentation and formulations for food enterprises. The main disadvantage of the above programs is the lack of scientifically-based optimization of formulations. Software complexes for managing database systems have been developed to allow the creation of reporting documents (Chief Expert, AVERS: calculation of the food menu, Vision-Soft: Nutrition in the kindergarten). These programs do not provide for optimizing recipes for both food and biological value.

Also, a patent search was carried out among the official registrations of computer programs. About 16 computer programs were found (the most suitable of them are presented in [19]-[21]), allowing similar calculations. The analysis of the descriptions of these programs revealed that none of the 16 programs is designed specifically for calculating the floury polycomponent mixture, nor does it carry out multicriteria optimization with the possibility of obtaining a set of conditionally optimal solutions.

Thus, a general drawback of existing programs and methods for optimizing the composition of mixtures is the lack of a subsystem (module) of optimizing the formulation according to the set of criteria for biological, mineral values, taking into account the assimilability of the ingredients introduced. The problems of optimizing the composition of the bakery mixture in the above-described works are solved by such mathematical methods as: simplex method, Monte Carlo method, Newton's method.

These methods have the following disadvantages:

1) The result is an only one variant of a mixture.

2) The use of only one objective function to optimize the solution and select options.

3) Essential changes are required in the model and solution when changing the initial data (changes in the number of components of the mixture or the number of amino acids taken into account).

The essence of the first drawback is the following: the optimal solution for a flour mix obtained by means of the model, which is appropriate to a given objective function, can show an unsatisfactory quality of bread in an experimental check. To solve this problem, it is expedient to obtain a set of solutions close to optimal. And only several solutions are selected for carrying out field experiments with the subsequent manufacture of bread and an assessment of its consumer properties.

As raw data, a list of raw materials is used to model the composition of the mixture in a manufacture of the product. For each raw component, the content of the most deficient amino acids is indicated in 1 gram of protein. For bread deficient amino acids are: lysine, threonine and the sum of methionine and cystine. The coefficients of the objective function are protein values in one gram of raw materials, as well as the boundary data for each component in the composition of the mixture. For example, consider a bakery product consisting of a set of raw components listed in Table I in which the content of deficient amino acids in 1 gram of protein is shown in Table II. In addition to the data restrictions should be included in the system: the optimal number of deficient amino acids in accordance with the FAO / WHO recommendation and the various characteristics of the mixture for the product (for example, the ratio of rye flour to wheat flour 60:40).

TABLE II. CONTENT OF DEFICIENT AMINO ACIDS IN RAW MATERIAL COMPONENTS FOR FLOUR MIXTURE

\begin{tabular}{|l|l|l|l|}
\hline \multirow{2}{*}{$\begin{array}{l}\text { Name of raw } \\
\text { materials }\end{array}$} & \multicolumn{3}{|l|}{ Indicator values } \\
\cline { 2 - 4 } & $\begin{array}{l}\text { lysine, mg in } \\
\mathbf{~ g}\end{array}$ & $\begin{array}{l}\text { threonine, mg } \\
\text { in 1 g }\end{array}$ & $\begin{array}{l}\text { methionine + } \\
\text { cystine, mg in } \\
\mathbf{~ g}\end{array}$ \\
\hline Rye flour & 34.34 & 36.36 & 42.63 \\
\hline Wheat flour & 29.60 & 24.00 & 34.96 \\
\hline Buckwheat flour & 42.06 & 31.75 & 45.22 \\
\hline Lentil & 71.67 & 40.00 & 51.59 \\
\hline Soy flour & 59.80 & 39.80 & 30.66 \\
\hline $\begin{array}{l}\text { Dry Skim Milk } \\
\text { (DSM) }\end{array}$ & 56.97 & 44.56 & 32.24 \\
\hline Sesame seeds & 28.56 & 39.59 & 45.05 \\
\hline Sunflower seeds & 34.30 & 42.75 & 37.97 \\
\hline Egg powder & 51.74 & 57.39 & 47.83 \\
\hline Gelatine & 43.20 & 14.90 & 1.70 \\
\hline Mustard seeds & 49.11 & 42.75 & 34.46 \\
\hline
\end{tabular}




\section{Additional restrictions:}

1) The content of the most deficient amino acids in a mixture of proteins should be as follows:

lysine $\geq 30 \mathrm{mg}$ per $1 \mathrm{~g}$ of protein

threonine $\geq 20 \mathrm{mg}$ per $1 \mathrm{~g}$ of protein

methionine + cystine $\geq 15 \mathrm{mg}$ per $1 \mathrm{~g}$ of protein.

2) The sum of all components of the mixture $=1$, that is 1 $\mathrm{g}$ of protein.

3) The amount of a mixture of rye and wheat flour $\geq 70$ or 0.7 units of the sum of all proteins.

4) The ratio of rye and wheat flour.

5) Permissible maximum dosages of additional raw materials, which do not adversely affect the quality of a baked bread.

The permissible maximum dosages of the selected raw material in the flour mixture for bread were determined experimentally. For this purpose, trial baking was done from rye-wheat mixes, replacing from 5 to $15 \%$ of wheat flour with buckwheat flour, lentils, soy flour, sesame seeds, sunflower seeds, egg powder, skimmed milk powder and substitution from 1.5 to $6 \%$ for mustard seeds and gelatin. The preparation of bakery products was carried out using methods adopted in bakery.

The data of the research results allowed us to establish that the permissible limits of the use of protein concentrators in the flour mix for bread are (not more than):

For mustard powder and gelatin - 3\%;

For the rest of ingredients $-15 \%$.

When developing mix composition options and selecting the minimum and maximum dose components, the following assumptions are taken into account:

- The amount of a mixture of rye and wheat flour should be less than $70 \%$;

- The total amount of raw material in the mixture is $100 \%$.

The mathematical formalization of the problem can be represented as follows:

$$
\begin{aligned}
& 0,999 x_{1}+0,125 x_{2}+\ldots 0,125 x_{n} \rightarrow \max \\
& \left\{\begin{array}{l}
34,9 x_{1}+\ldots 43,3 x_{n} \geq 30 \\
36,36 x_{1}+\ldots+43,3 x_{n} \geq 20 \\
42,6 x_{1}+\ldots+1,7 x_{n} \geq 15 \\
x_{1}+\ldots x_{n} \geq 0,7 \\
\ldots \ldots \ldots \ldots \ldots \ldots \\
0,05<x_{n}<0,4 \\
x_{1}+\ldots+x_{n}=1
\end{array}\right.
\end{aligned}
$$

\section{REalization of the Program of the Automated SYSTEM OF SCIENTIFIC RESEARCH}

The resulting problem was solved by a simplex method with an artificial basis related to numerical optimization methods for solving linear programming problems. The computer complex of the automated research system allows us to obtain a set of solutions to the optimization problem, which will allow us to choose the optimal solution based on a comprehensive indicator of the quality of a final bakery product.

Proceeding from the foregoing, the proposed method of the bread composition modeling should have the following properties:

1) Invariance of the solution from the number of amino acids accounted for and the number of components used in the mixture.

2) Acceptable time of algorithmic implementation of the method.

3) The ability to quickly adapt and change the method when adding new mix restrictions or changing the current ones.

4) The possibility of obtaining several variants of the mixture for further selection of the optimal of them according to organoleptic properties.

5) The ability to quickly configure and change the parameters of the algorithm implementation of the method.

On the base of the developed mathematical model and the proposed algorithm for calculating the polycomponent mixture, a prototype of an automated research system was developed and implemented to calculate the optimized protein amino acid composition of the flour mixture. This system was developed using a high-level programming language ObjectPascal with the use of IDEBorlandDelphi 7.0.

This system allows you to download various data on the components of the mixture, edit the existing data and values, save the results of the studies, and flexibly conduct the procedure itself.

For this system, input and output file formats, internal structures for optimal storage and processing of information have been developed, also a calculation algorithm has been implemented that shows results that adequately reflect known theoretical knowledge and practical results in the production and analysis of polycomponent flour mixtures.

An example of the developed automated research system is shown in Fig. 1.

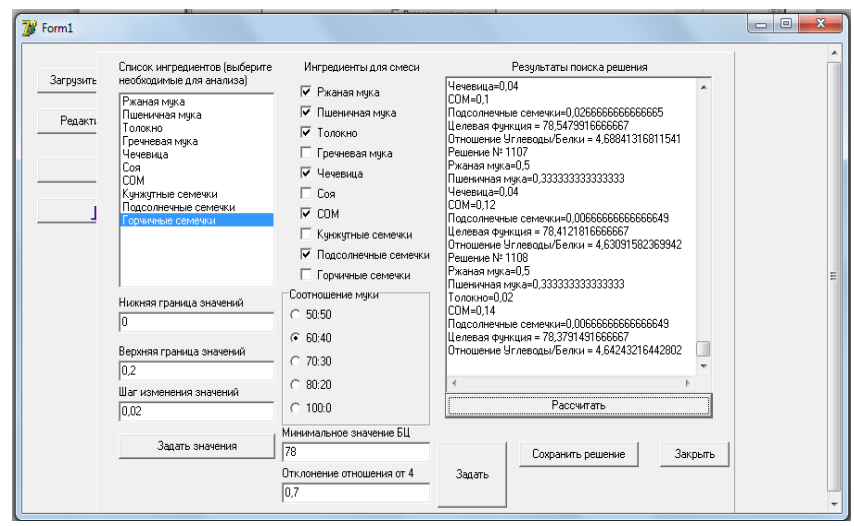

Fig. 1. Results of work of the automated system of scientific research. 




Fig. 2. Characteristics of the biological value of flour mixes generated by the software package.

As a result of the automated research system work, more than 100 flour mixtures were generated. After the analysis of the calculated data, 10 of them were selected with an indicator of biological value of at least $75 \%$.

The biological values of the calculated mixtures are shown in Fig. 2. The control sample was a rye-wheat mixture without additives.

It is established that the use of the software package allows creating recipes for rye-wheat bread with a biological value of $6.12-17.66 \%$ higher than that of the control sample. These recipes were used to make bakery products in ways adopted in bakery. It is determined that the test bakery products have physicochemical and organoleptic quality indicators not lower than the established norms for this type of product.

\section{CONCLUSION}

The developed computer program of the automated system of scientific researches allowed optimizing the composition of flour mixes for bakery products from a mixture of rye and wheat flour by biological value. This was achieved by mathematical formalization of the problem, taking into account the limitations on the optimal content of nontraditional raw materials and the number of amino acids deficient for bakery products, such as lysine, threonine and the sum of methionine with cysteine. This allowed to generate flour mixtures with a $6.12-17.66 \%$ higher biological value (compared to the control sample and quality indicators traditional for this type of product).

Further development of these studies will consist in bringing the developed prototype of the automated research system to industrial design, conducting a series of studies on the resulting finished product (bread), and conducting research on consumer preferences of prepared formulations having optimized amino acid composition for launching such products in batch production.

Also an important area of research will be the integration of the developed automated system with automated control systems for technological processes used at bakery enterprises. This will allow carrying out a continuous process from the moment of calculating the parameters of a polycomponent flour mixture to launching a new product into production and adjusting the corresponding parameters of the equipment (for example, dispensers). Thus it is necessary to develop appropriate software and hardware interfaces for the developed system with software and hardware industrial equipment.
Another possible direction of research is the completion of the system as a cloud service on the Internet. Such a solution will allow various enterprises and scientists to conduct research at their workplaces without the need to install a developed automated system. Also, such a mechanism will allow accumulating a database of various formulas of bakery mixtures, analyze them, assess their taste and consumer qualities by various researchers and enterprises, and accumulate integral estimates for each variant of the mixture.

\section{ACKNOWLEDGMENT}

The applied scientific research work was supported by the Ministry of Education and Science of Russian Federation within the framework of the implementation of the federal target program "Research and Development in Priority Areas for the Development of Russian Science and Technology Complex for 2014-2020" under the agreement on subsidy No. 14.577.21.0256 of 26 September 2017. The unique identifier of the exploratory experimental research work RFMEFI57717X0256.

\section{REFERENCES}

[1] Casala E., Matthys C., Péter S., Baka A., Kettler S., McNulty B., Stephen A.M., Verkaik-Kloosterman J., Wollgast J., Berry R. and Roe M. Monitoring and addressing trends in dietary exposure to micronutrients through voluntarily fortified foods in the European Union. Trends in Food Science \& Technology, 2014, vol. 37, no. 2, pp. 152-161.

[2] Diplock A.T., Aggett P.J., Ashwell M., Bornet F., Fern E.B. and Roberfroid M.B. Scientific concepts in functional foods in Europe: consensus document. British Journal of Nutrition, 1999, vol. 81, no. 1, pp. 1-27.

[3] Energy and protein requirement Report of a joint FAO/WHO ad hoc expert consultation/ WHO tech/ Ref. Ser. №724 - Geneva: WHO, 1985.

[4] Gao, H., Modelling strategies for nano- and biomaterials, in European White Book on Fundamental Research in Materials Science, Germany: Max Planck Inst., 2001, pp. 144-14.

[5] Hu R. Food product design: a computer-aided statistical approach. CRC Press, 1999, $240 \mathrm{p}$.

[6] Innovation trends in the food industry: The case of functional foods. Available

from: https://www.researchgate.net/publication/257346264_Innovation_trends in_the_food_industry_The_case_of_functional_foods [accessed Nov 262017 .

[7] Oliviero T.A., Verkerk R. and Dekker M. Research approach for quality based design of healthy foods. Trends in Food Science \& Technology, 2013, vol. 30, no. 2, pp. 178-184.

[8] Pokrovsky, A. A. Chemical composition of food products. Moscow: Food industry, 1979. - 289 p.

[9] Rickman, J. M. and LeSar, R., Computational materials research, Ann. Rev. Mater. Res., 2002, vol. 32, no. 1. doi: 10.1146/annurev.mr.32.010101.100002.

[10] Ronteltap A., Sijtsema S.J., Dagevos H. and de Winter M.A. Construal levels of healthy eating. Exploring consumers' interpretation of health in the food context. Appetite, 2012, vol. 59, no. 2, pp. 333-340.

[11] Kiselev V.M. Evolutionary methodology for designing functional food products. Food Industry, 2009. vol. 11, pp. 57-59.

[12] Medvedev P.V. System analysis of raw material properties and scientific fundamentals of bread quality management by using protein concentrates. Author's abstract, Kemerovo, 2004, 26 p.

[13] Polyakova E.D. Use of hydrolysed corn gluten in food technologies. Technology and Commodity Research of Innovative Food Products, 2012, vol. 6, pp. 25-30.

[14] Sanina T.V. Optimization of the formulation of a composite mixture. Bakery of Russia, 2007, vol. 1, pp.18-19. 
[15] Sanina T.V. Designing bakery products of high nutritional value. Storage and processing of agricultural raw materials, 2008, vol. 4, pp. 65-67.

[16] Voropaeva O.N. Development of technology of bakery products with flour composite mixtures: the author's abstract. Voronezh, 2008.

[17] Korotkova O. Development of technology and commodity assessment of bakery mixtures and products based on them. Author's abstract. Kemerovo, 2011, 26 p.

[18] Demina I.A. Research and calculation of the composition of flour composite mixtures using the problems of linear programming MS Excel. Vestnik KASU, 2009, vol. 1.

[19] Dmitry Popov. Optimization of the fatty acid composition of a multicomponent food system [Computer program] / N.S. Rodionova,
D.S. Popov, E.S. Popov, E.A. Pozhidaeva. - № 2015660193. Registered in the Register of Computer Programs on 24.09.2015.

[20] Kasyanov G.I. Determination of the biological value of the product by analyzing the amino acid composition with the determination of the limiting amino acids by the methods of dynamic programming for scanning heterogeneities [Computer program] / G.I. Kasyanov, O.V. Kosenko, S.V. Belousova, O.N. Zyuzina, N.S. Nikolenko, L.V. Hobta. No. 2014611486. - Registered in the Register of Computer Programs on 04.02.2014.

[21] Kurakin M.S. Calculation of nutritional value of diets [Computer program] / M.S. Kurakin, P.A. Nekrasov. - No. 2013618379. Registered in the Register of Computer Programs on 06/09/2013. 